\title{
Analysis of the Performance Indicators of the PV Power System
}

\author{
Saad Odeh \\ Sydney Institute of Business and Technology, Western Sydney University, Sydney City Campus, Australia \\ Email: S.Odeh@city.westernsydney.edu.au
}

How to cite this paper: Odeh, S. (2018) Analysis of the Performance Indicators of the PV Power System. Journal of Power and Energy Engineering, 6, 59-75. https://doi.org/10.4236/jpee.2018.66005

Received: May 7, 2018

Accepted: June 25, 2018

Published: June 28, 2018

Copyright $\odot 2018$ by author and Scientific Research Publishing Inc. This work is licensed under the Creative Commons Attribution International License (CC BY 4.0).

http://creativecommons.org/licenses/by/4.0/

\section{c) (i) Open Access}

\begin{abstract}
The energy assessment of the PV power systems is carried out by using different types of performance indicators that benchmark the output of these systems against the PV panel maximum output at hypothetical operation conditions. In this paper, a comparative analysis of six types of performance indicators is conducted and a new performance indicator which considers PV panel slope and orientation is proposed. The proposed indicator is benchmarking the PV system actual output against the maximum output of the same system if it would operate in two axis tracking mode. The proposed performance indicator is used to develop a friendly user calculator of PV system output that can be used by, energy providers and PV system installers to evaluate the output of the PV grid connect network. The advantage of the developed calculator is highlighted by a case study that estimates energy capacity of different residential rooftop PV systems installed in a residential suburb in Sydney.
\end{abstract}

\section{Keywords}

PV Roof Top, Solar Power, Performance Indicator, PV Grid Connect, Peak Sun Hours

\section{Introduction}

The performance of the solar energy systems such as the PV power generators is quite low when it is compared with the conventional systems performance such as Diesel engines due to the energy loss associated in the conversion of light photons energy into electrical energy by the PV semiconductor cells. Another source of energy loss in the PV power systems is the optical losses which is the deviation of the input solar radiation from the PV panel aperture. Therefore, special performance indicators that consider factors related to the PV power 
systems are used when assessing these systems. Some of these factors are related to weather conditions such as irradiation, and other factors are related to system losses such as PV panel efficiency [1] [2] [3]. In a commercial size PV system the effect of system losses increases which requires steadier monitoring and assessment to pinpoint the source of loss instantly. Reference [4] examined the annual performance of a $110 \mathrm{KW}$ PV commercial system using annual specific yield as the performance indicator. The annual yield value for this system was found equal to $1731 \mathrm{kWh} / \mathrm{kWp}$ which is considered viable for the local application of the PV power generation. Three types of software: Sunny design, SAM, and Blue Sol were used to simulate the system performance and cost analysis. The simulation showed that the difference in the results between the three PV system performance simulators is about $3 \%-5 \%$. Long term assessment of $171 \mathrm{~kW}$ grid connected system installed in a remote area was conducted [5]. The annual performance ratio of that system was found equal to $67.4 \%$, annual capacity factor $15.3 \%$, and annual final yield was found equal to $1336.6 \mathrm{kWh} / \mathrm{kWp}$, which is close to similar plants in Europe. Performance analysis based on capacity factor and performance ratio was carried out for an existing $20 \mathrm{~kW}$ industrial PV rooftop system [6]. The study showed that there are factors other than the clearness index affecting the power generation such as: variation in ambient temperature, partial shading, and accumulation of dust on the PV module surface. The application of PV performance indicators on residential PV power generators was reviewed by analysing reported data from $6868 \mathrm{PV}$ systems in France [7]. The average annual yield for these systems was found equal to $1163 \mathrm{kWh} / \mathrm{kWp}$. The mean performance ratio and the performance index were found equal to $76 \%$, and $85 \%$ respectively. Similar work was conducted to review the performance pf 158 PV residential system in Belgium [8]. The results showed similar values for the performance ratio is $(78 \%)$ and the performance index was $(85 \%)$, however the annual yield was found lower $(902 \mathrm{kWh} / \mathrm{kWp}$ ) due to the change in irradiation. Long term assessment of a residential roof top solar PV system was conducted based on 4 years of operation data in Sydney [9]. The annual average performance ratio was found equal to $77 \%$ and the annual yield was equal to $1391 \mathrm{kWh} / \mathrm{kW}$. The output of an existing rooftop grid connected PV system was recorded and analysed by ref [10] to evaluate the annual final yield, the performance ratio, the PV module efficiency, and the system efficiency in Sydney. The result of these performance indicators evaluated at this site showed superiority among other sites in Europe given by ref [11].

This study is an extension to the work of ref [10] to develop the existing performance indicators to a new indicator that considers PV panel's orientation. This indicator correlates the actual output of the PV power generator with its output when the PV panels have two axis solar tracking mechanism. Although the tracking mode cannot be applied to some designs of PV systems such as the inclined roof designs it represents the actual reference that can be applied to benchmark the system performance. The proposed performance indicator is used to develop a friendly user calculator of PV system output that can be used 
to estimate the output of the PV grid connect network.

\section{Review of the Performance Indicators of the PV Power System}

The traditional method of assessing the power generator performance is by estimating the ratio of system output (electricity) during a period of time (such as; daily, monthly, or yearly) to the generator maximum capacity for the same period of time. Although this type of assessment method is applicable to the different types of power generator such as: oil, gas, coal, renewable ... etc., solar power generators require some other considerations. The intermittent solar irradiation, and other weather conditions affect significantly the long term performance of PV power generators. The six major performance measures found in the literature can be summarized as follows:

\subsection{System Efficiency ( $\left.\eta_{\text {system }}\right)$}

Is the ratio of the output energy of the PV system to the energy of the incoming irradiation incident on the same PV panels' area and is given in the following form [1] [2] [3] [12] [13] [14]:

$$
\eta_{\text {system }}=\frac{\text { Generated enery from the PV system in } \mathrm{kWh}}{\text { Solar irradiation incident on the PV array's area in } \mathrm{kWh}}
$$

The PV system efficiency is quite low compared with other conventional power generators and depends significantly on the PV panel efficiency which is in the range of $(14 \%-17 \%)$ at standard test conditions and inverter efficiency which is in the range of $(95 \%-98 \%)$ at actual operation condition [15]. This method is useful when it is required to compare the different designs and brands of PV systems. However, from the enduser perspective this method of assessment is not a good tool for power system performance comparison since the conventional power units has much higher energy conversion efficiency than the solar energy systems.

\subsection{Solar Fraction (SF)}

Is the amount of energy produced by the PV system to the amount of load required at the respective site [1] [16]. The value of solar fraction depends mainly on the PV system contribution to the site load and cannot be used to compare system performance with other similar systems at different sites. Solar fraction can be represented by the following equation,

$$
S F=\frac{\text { Generated eneryfrom the PV system in } \mathrm{kWh}}{\text { Site energ load(heat and/or electricity) in } \mathrm{kWh}}
$$

There is no specific range for the value of solar fraction because it depends on the percentage of solar contribution to the site energy load. From the economic perspective $S F$ cannot approach $100 \%$ especially in residential application due to the requirement of the costly energy storage battery bank to cover the periods of 
low or zero irradiation.

\subsection{Capacity Factor $\left(C_{F}\right)$}

Is defined as the ratio of the actual annual energy output from The PV system to the energy generated by the PV system when it operates at its full rated power, i.e., 24 hours and seven days a week [6] [11]. Based on this definition the equation of $C_{F}$ is given by:

$$
C_{F}=\frac{\text { Generated energy from the PV system }(\mathrm{kWh}) / \text { year }}{\mathrm{PV} \text { array maximum capacity }(\mathrm{kW}) \times 8760 \mathrm{~h} / \text { year }}
$$

The definition of this performance indicator shows that the expected value of $C_{F}$ cannot be high because the actual system capacity is bound by the number of sunshine hours. Reference [11] showed that the average yearly $C_{F}$ is in the range of $0.1-0.2$.

\subsection{Performance Ratio $\left(P_{R}\right)$}

It is the actual amount of energy produced by a PV system to the energy produced by the same system when operating continuously at standard test conditions (STC) and the same global irradiation [2] [3] [12] [15] [17] therefore,

$$
P_{R}=\frac{\text { Generated energy from the PV system }(\mathrm{kWh})}{\text { Total incident Global radiation on PV array }(\mathrm{kWh}) \times \eta_{\mathrm{STC}}}
$$

$\eta_{\mathrm{STC}}$ is PV panel efficiency at standard test conditions.

$P_{R}$ is independent of system size and is typically evaluated on a monthly or yearly basis by considering system total losses. Equation (4) shows that $P_{R}$ does not change a lot with the type of the PV system and depends basically on the constant STC values. In large scale commercial systems $P_{R}$ can be used to investigate the occurrences of component failures by calculating it for smaller intervals, such as weekly or daily. The average value of the performance ratio found in the literature is within the range of 0.6 to 0.9 [6] [11] [15] [18].

\subsection{The Final PV System Yield or the PV System Specific Power Production $\left(Y_{f}\right)$}

Is the actual net energy output during a certain period of time (i.e., daily, monthly) divided by the maximum installed power capacity of the PV array and has the unit $\left(\mathrm{kWh} / \mathrm{kW}_{\mathrm{c}}\right)$. This performance indicator can be presented by the following equation [3] [12].

$$
Y_{f}=\frac{\text { Generated energy from the PV system }(\mathrm{kWh})}{\mathrm{PV} \text { array maximum capacity }(\mathrm{kW})}
$$

The PV array maximum capacity is estimated from the PV panel maximum output in $\mathrm{kW}$ multiplied by the number of panels in the array field. System yield is a convenient way to compare the energy produced by the PV systems of different brands at different latitudes. The average yearly yield was found in the range of $800-1100 \mathrm{kWh} / \mathrm{kW}$ [15] and the average daily yield in Australia is in 
the range of $3-5.2 \mathrm{kWh} / \mathrm{kW}$ (APVI 2017).

\subsection{Performance Index (PI)}

Is the performance of the power generator when considering thermal losses due to PV panel overheating and the invertor operation losses. It allows comparing the PV system under different climatic and installation conditions. The value of $P I$ was found in the range of $84 \%-85 \%$ and it can be calculated by [7] [8].

$$
P I=\frac{\text { Generated energy from the PV system in }(\mathrm{kWh})}{\text { Total incident Global radiation on } \mathrm{PV} \text { array }(\mathrm{kWh}) \times \eta_{\mathrm{PV}} \times \eta_{\text {inv }}}
$$

where, $\eta_{\mathrm{PV}}$ is PV panel efficiency at actual surface temperature, and $\eta_{\text {inv }}$ is $\mathrm{DC} / \mathrm{AC}$ invertor efficiency.

\section{Analysis of the Performance Indicators}

A comparison between the six PV performance indicators was conducted using collected data of a rooftop residential system operating in Sydney since 2011 [9]. To find the effect of ambient temperature on system operation, the average of highest daily temperature was deducted from Bureau of Meteorology [19] for the same period of system operation (2011 to 2015) and presented in Figure 1. It is clearly shown that there is high consistency in system efficiency during the four years of operation with small dips and rises based on the weather conditions. Figure 1 shows that the effect of ambient temperature represented by average of highest daily temperature is quite significant during summer since it causes an increase in PV panel temperature and consequently a drop in system efficiency [1] [20]. The increase in PV panel temperature increases the internal electric resistance of the panel and therefore drops the panel output. The average of the combined efficiency of PV panels and inverter system which is the AC output divided by global irradiation found in this work is equal to about $13.9 \%$ as shown in Figure 1.

The collected data of the rooftop PV system was used to verify the performance simulation estimated by the PVSYST package [21]. It can be concluded from Figure 2 that PVSYST correlates the measured data accurately in most of the year with relative error in the range of $( \pm 4.4 \%)$. The maximum error occurs during the winter quarter which is about $12 \%$ due to the difference between the actual weather data and the data bank of the PVSYST package. Another source of error between the measured and the estimated values of the PV system output is the accumulation of dust on the surface in no rain season and/or the partial shading that can take place from the adjacent objects which reduces the amount of solar irradiation incident on the PV panel.

The PVSYST model for the rooftop PV system was used to analyze the six PV performance indicators. The results of this analysis are presented in Figure 3 and Figure 4 which show that there are two different profiles for system performance:

1) $S F, C_{F}$ and $Y_{\dot{f}}$ Which show that the PV system has minimum performance in winter and maximum system performance in summer. This trend of per- 
formance is due to the actual PV system output which is benchmarked to the system operation at an ideal or arbitrary condition.

2) $P_{R}, P I$ and $\eta_{\text {system }}$ : These two indicators show that the maximum system performance occurs in winter while the minimum system performance occurs in

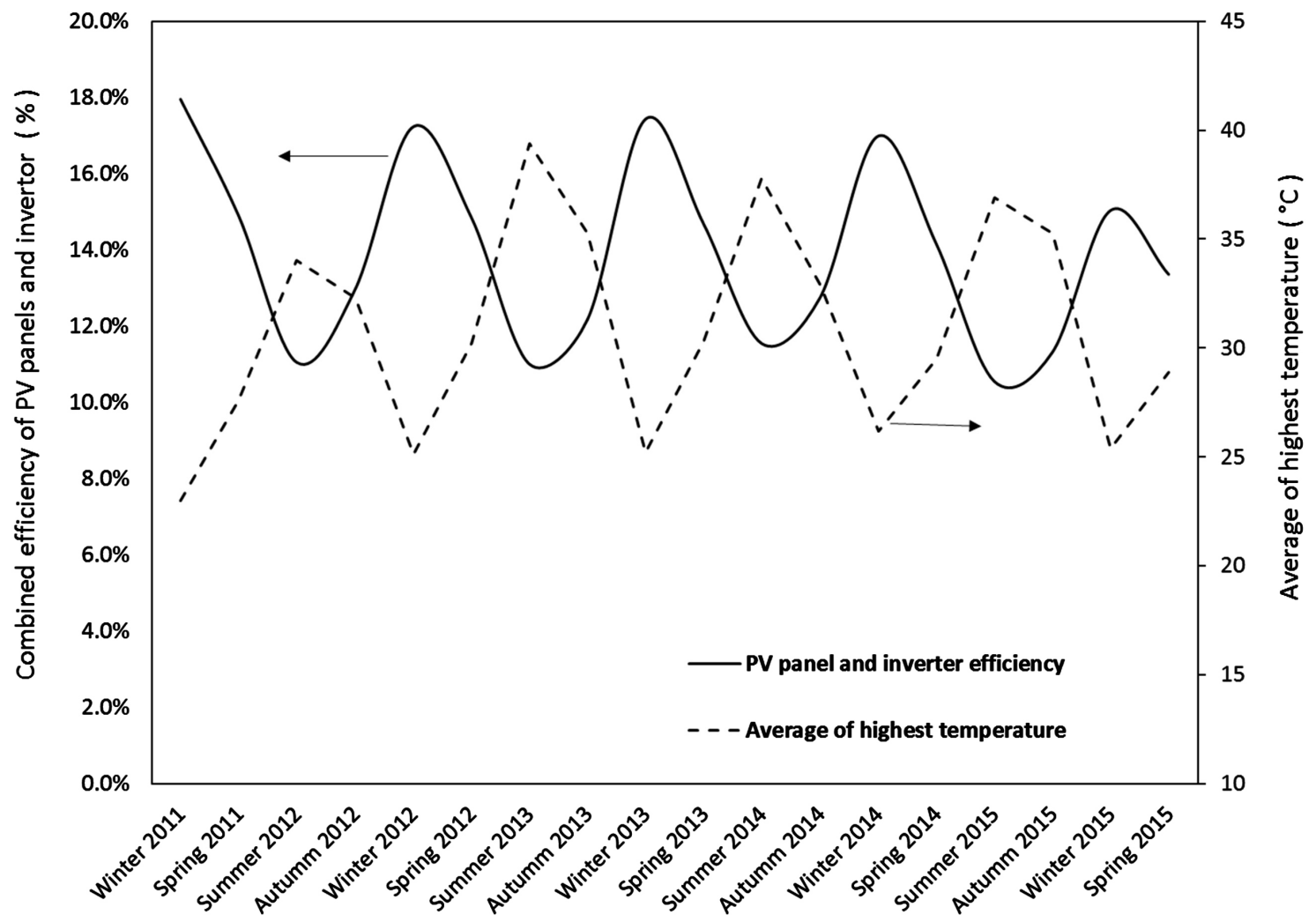

Figure 1. The combined efficiency of the PV panels and invertor in different seasons-Sydney.

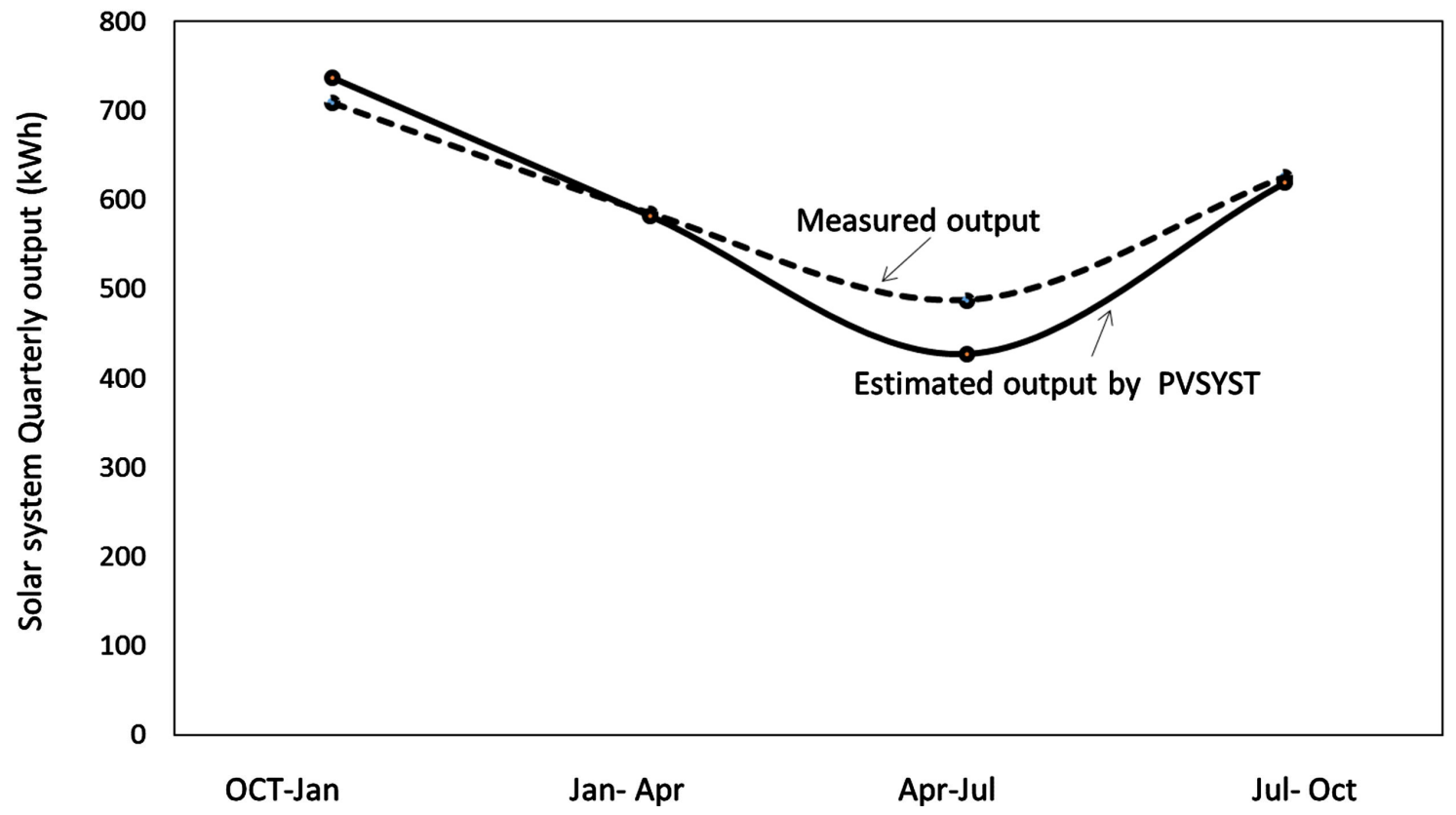

Figure 2. Verification of the rooftop PV output simulation. 


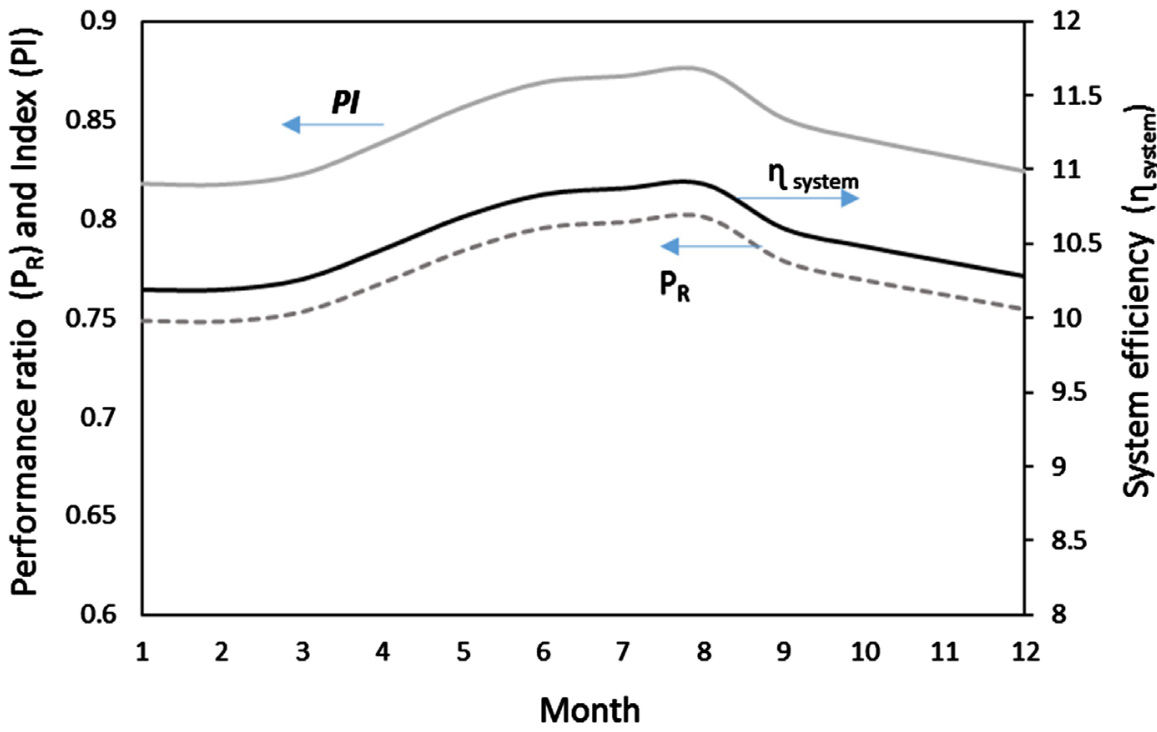

Figure 3 . System yearly performance using $P_{R}, P I$ and $\eta_{\text {system }}$ indicators.

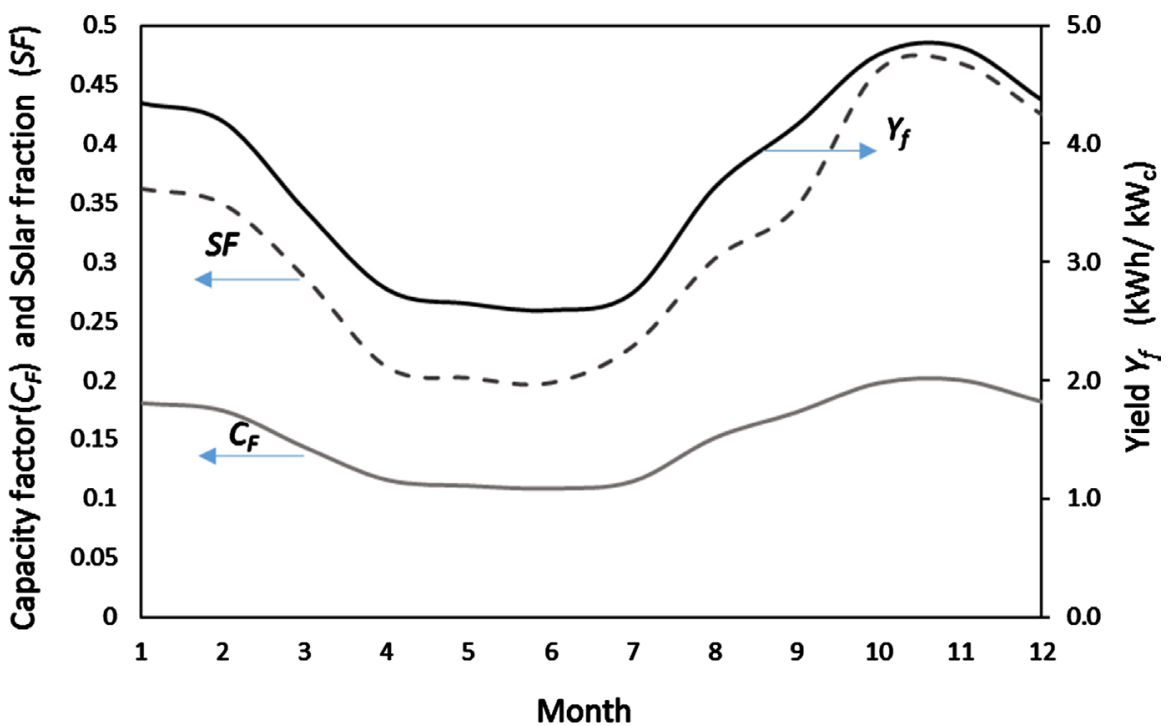

Figure 4. System yearly performance using $S F, C_{F}$ and $Y_{f}$ indicators.

summer. This trend of system performance is due to the fact that these indicators use input irradiation as a reference of comparison.

The analysis shows that the six performance indicators do not benchmark the PV panel output with its maximum output at the identical orientation angles, i.e., inclination and azimuth angles which can be achieved with a solar tracker. This parameter is quite significant when it is required to compare the output of rooftop PV systems for different roof designs. If the same design of PV system assessed at different latitudes using the six performance indicators different performance profile will be resulted by each indicator. The end user will not be able to comprehend why the PV system is not performing well art high irradiation condition compared with other lower irradiation sites. More clarification to this point is shown by Figure 5 and Figure 6 which represent the performance values 


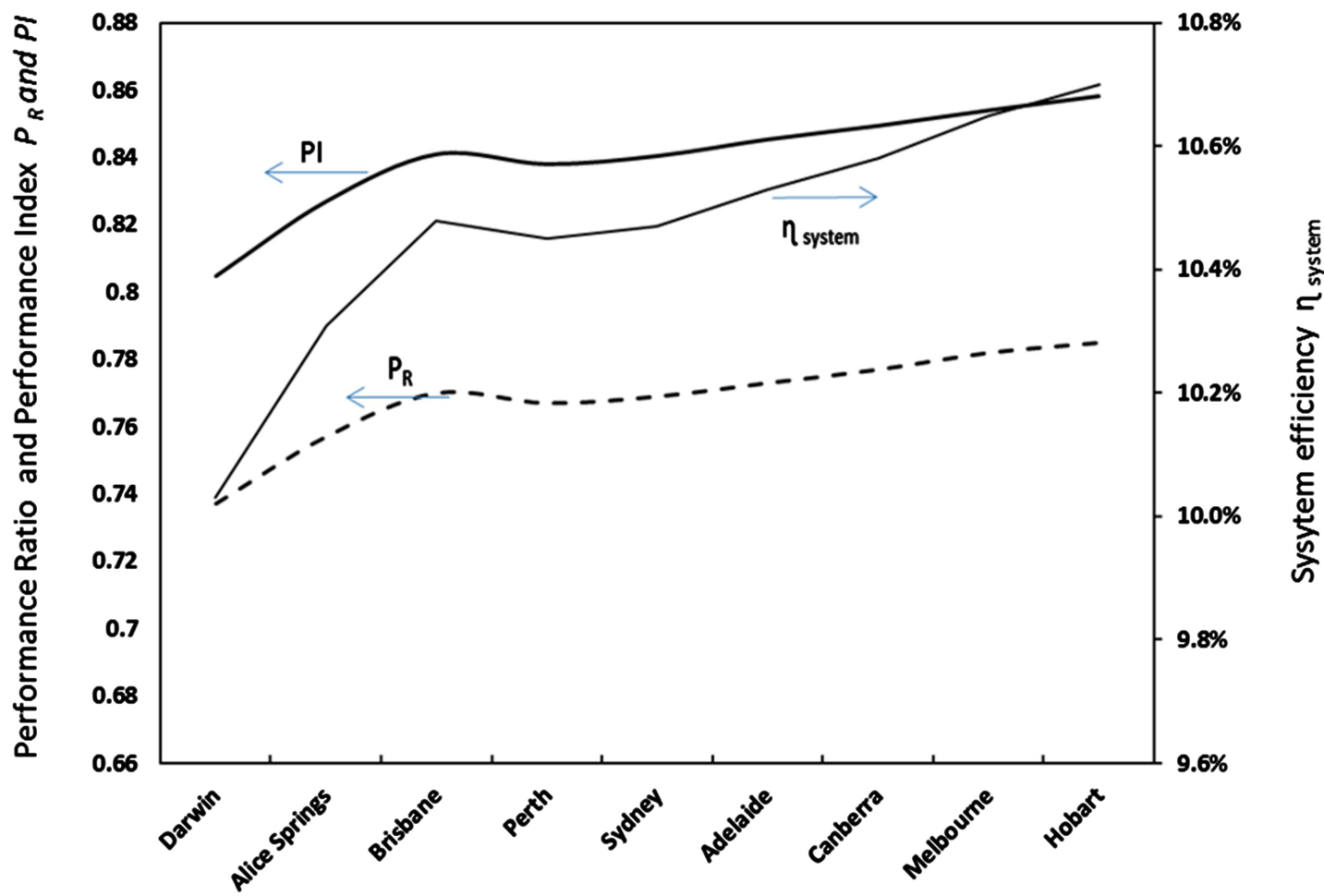

Figure 5. The effect of latitude on the performance indicators $P R, P_{I,}$ and $\eta_{\text {system }}$.

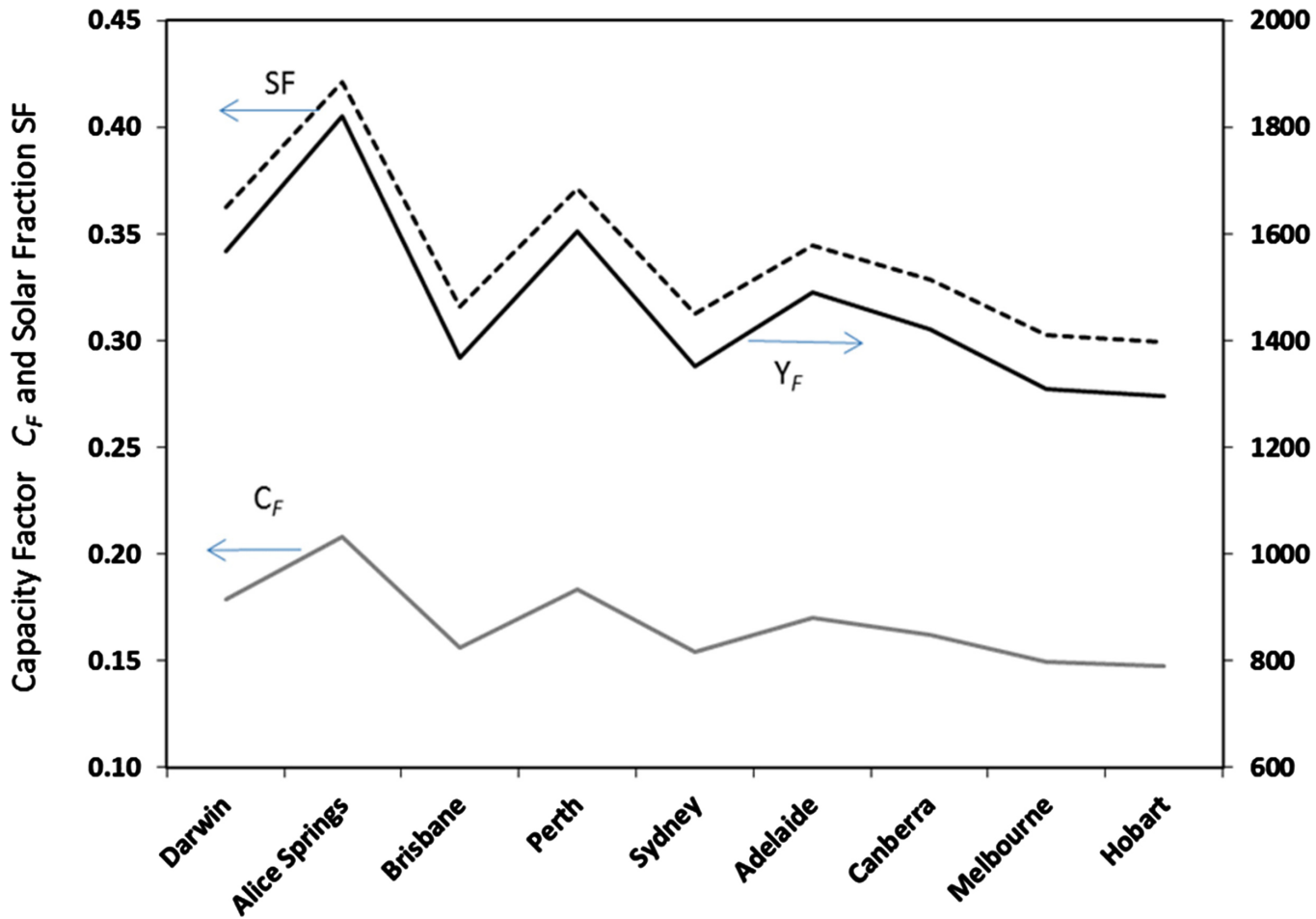

Figure 6. The effect of latitude on the performance indicators $S F, C_{F}$ and $Y_{F}$.

at different latitudes. It is clear that some indicators (group 1) correlated proportionally with latitude angles. However, group 2 shows fluctuation and the general trend shows a decrease of performance with latitude. 


\section{Drawbacks in the PV Performance Indicators}

The review of the different performance indicators $\left(P_{R}, \eta_{\mathrm{system}}, S F, C_{F}, Y_{F}\right.$ and $\left.P I\right)$ found in the literature shows that they do not provide the end users with a scale that describes the actual capacity of the PV generators due to the following drawbacks:

1) The first drawback in some of the performance indicators is that they benchmark the performance of the solar PV system to the standard test condition (STC) given in Table 1. Five (STCs) are being used in testing the PV performance: zero incident angle, fixed solar irradiation, fixed ambient temperature, fixed air mass, and zero system losses. During actual operation of the solar PV system the standard operation conditions ( 1 to 5) in Table 1 cannot be achieved constantly, i.e., they are laboratory virtual conditions. Considering these arbitrary conditions in the performance indicator of a solar PV system, it will underestimate the actual value of the system performance and give the end user a false impression about the PV system capacity.

2) The different performance indicators do not include in their definition the effect of panel orientation and inclination angles which are significant parameters in residential or small scale commercial systems. There is no tool that can give the end user a measure to compare between the different designs of PV frame.

3) The time period used in Equation (3) does not describe the actual operation time of the PV system. This point can be well clarified by the following equation which represent the energy capacity of conventional power generators such as: Diesel, gas, and petrol engines,

$$
E_{c}=P_{c} \times \text { number of operation hours }
$$

where, $E_{c}$-energy capacity $(\mathrm{kWh})$

$$
P_{c} \text { - power capacity }(\mathrm{kW})
$$

Equation 7 shows that energy capacity $\left(E_{c}\right)$ may reach its maximum when the power generator operates full time (daily, monthly or yearly). However, this is not possible in case of the solar PV system since its output is limited by two factors; the number of sun shine hours during the year, and the PV array orientation angles. Therefore, it is not correct to specify the energy capacity of a PV panel by referring to Equation (7) because these two factors frame its capacity and no energy can be generated beyond this limit. To clarify this further, a system of PV array size $(1 \mathrm{~kW})$ cannot produce $1 \mathrm{kWh}$ constantly during the 24 hours and the 365 days of the year.

Based on these three drawbacks and from the end-user perspective PV system capacity must be readjusted for each site based on its individual operation condition. The only STC of Table 1 that can be achieved in actual PV operation, is the first condition by using solar tracking system that tracks the solar beam and keeps solar incident angle always zero. This design is most likely possible in case of flat roof design or in the case of ground mount PV arrays field for commercial application. The common PV design of most of the residential systems in Australia is 
Table 1. Standard test condition STC.

\begin{tabular}{llll}
\hline \multicolumn{1}{c}{$\begin{array}{c}\text { Condition } \\
\text { type }\end{array}$} & \multicolumn{2}{c}{ STC } & \multicolumn{1}{c}{ Real condition } \\
\hline 1 & $\begin{array}{l}\text { Solar incident } \\
\text { angle }\end{array}$ & $\begin{array}{l}\text { Always zero, irradiation beam } \\
\text { always normal to the PV } \\
\text { panel, (can be achieved in real } \\
\text { operation) }\end{array}$ & $\begin{array}{l}\text { Variable, and depends on time, date, and site } \\
\text { latitude. In case of roof top system, roof } \\
\text { orientation and inclination governs system } \\
\text { capacity. }\end{array}$ \\
2 & $\begin{array}{l}\text { Solar } \\
\text { irradiation } \\
\text { (cannot be achieved in real } \\
\text { operation) }\end{array}$ & $\begin{array}{l}\text { Variable and depends on the time, date, and site } \\
\text { latitude. Limited sun shine hours bound system } \\
\text { capacity. }\end{array}$ \\
Ambient & $\begin{array}{l}\text { Always } 25^{\circ} \mathrm{C} \text {, (cannot be } \\
\text { achieved in real operation) }\end{array}$ & $\begin{array}{l}\text { Variable and depends on the time, date, weather } \\
\text { condition and site latitude. Higher ambient } \\
\text { temperature degrades PV panel efficiency and } \\
\text { reduces system output. }\end{array}$ \\
& $\begin{array}{l}\text { Air mass } \\
\text { Coefficient } \\
\text { (AM) }\end{array}$ & $\begin{array}{l}\text { Always equal to } 1.5 \text { (cannot } \\
\text { be achieved in real operation) }\end{array}$ & $\begin{array}{l}\text { Variable and depends on the time, date, and site } \\
\text { latitude. Higher AM with higher latitudes. }\end{array}$ \\
$\begin{array}{l}\text { System losses } \\
\text { (eg., wiring, } \\
\text { inverter) }\end{array}$ & $\begin{array}{l}\text { Always Zero (cannot be } \\
\text { achieved in real operation) }\end{array}$ & $\begin{array}{l}\text { Variable and depends on the design and } \\
\text { location of PV panels, inverter, and grid meter. }\end{array}$ \\
\hline
\end{tabular}

the rooftop arrangement where the inclination and the orientation of the PV panels are bounded by the actual roof design which must comply with the roof slop angle specified by the building code [22]. The standard residential roof slope angle is between $20^{\circ}-24^{\circ}$ which falls within the accepted optimum angle range at latitudes such as Brisbane, $27.5^{\circ}$, or Alice springs, $23.3^{\circ}$. The common type of PV frame structure of the commercial systems in Australia is the fixed orientation design which considers the true north as the optimum PV panel azimuth angle and the latitude angle as the optimum PV panels slope to achieve maximum annual output from the PV power generator.

\section{Performance Compliance Ratio $P_{C R}$}

The PV system performance when its' PV panels operate with two axis tracking mode can be used as reference point to benchmark the performance of different designs of the PV system at different sites. The performance ratio $\left(P_{R}\right)$ and the capacity factor $\left(C_{F}\right)$ given by Equation (3) and Equation (4) can be readjusted and represented in terms of a new performance indicator called, performance compliance ratio $\left(P_{C R}\right)$ given by the following equation:

$$
P_{C R}=\frac{E_{p}}{E_{\max }}
$$

where,

$E_{P}$-Actual energy produced by the PV system (kWh/year)

$E_{\max }-$ Actual energy produced by the same PV system with two axis solar tracking mode (kWh/year).

It is important to point out that both $E_{p}$ and $E_{\max }$ consider the different system 
losses in their values.

The performance compliance ratio $\left(P_{C R}\right)$ given by Equation (8) is a measure of the compliance of the PV system output to the optimum design (solar tracking system) output. Therefore, if a system operates at $P_{C R}=0.7$ it means that there is $30 \%$ deviation from the maximum capacity design. Furthermore, if the PV system operates in two axis tracking mode then its $P_{C R}=1$. This indicator provides the system designers, installers, and energy providers with a tool to draw a preliminary picture of the solar electricity produced by different suburbs or states without using the sophisticated softwares. A better understanding of the advantage of using $P_{C R}$ rather than the conventional performance indicators can be achieved by comparing between the monthly performance results as described in Figure 7. The value of $P_{C R}$ does not follow steady trend as in PR which my give the end user a misleading information about how far is the PV system away from the maximum capacity output.

The performance compliance ratio of the adopted rooftop model in this study was calculated at different major cities in Australia. Figure 8 shows that the highest $P_{C R}$ occurs in Brisbane because the rooftop system output at this latitude become closer to the tracking mode system output. Although other sites like Alice Springs have higher irradiation but the performance compliance ratio of its rooftop PV system is minimum, compared with other sites in Australia. However, it can be observed from Figure 8 that the maximum difference in $P_{C R}$ between the different sites is only $6 \%$ because the roof azimuth angles was fixed for all sites in this analysis.

The $P_{C R}$ and roof orientation angles charts are presented in Figure 9 and Figure 10 for Brisbane and Sydney. These charts shows that optimum $P_{C R}$ occurs

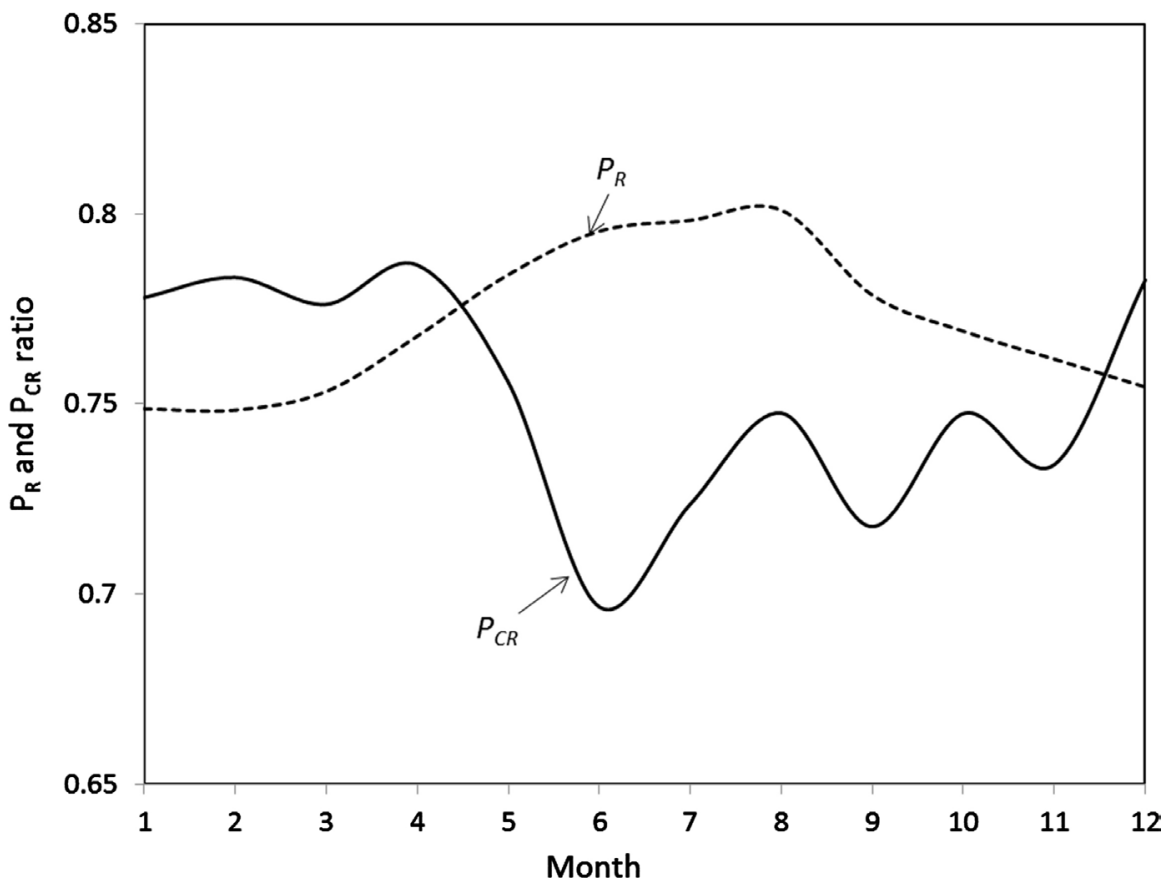

Figure 7. Comparison between $P_{R}$ and $P_{C R}$ for a rooftop system. 


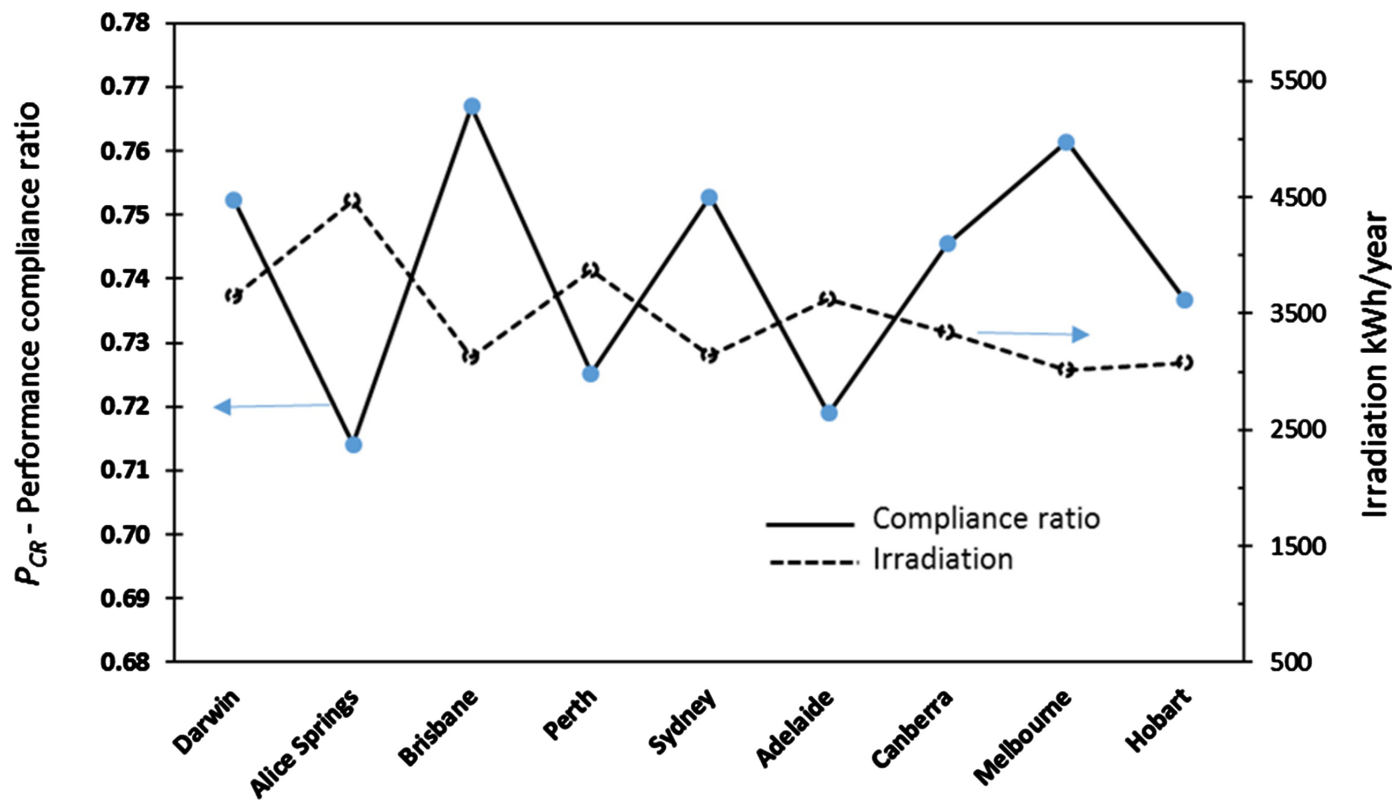

Figure 8. Performance compliance ratio and Irradiation at different sites in Australia.

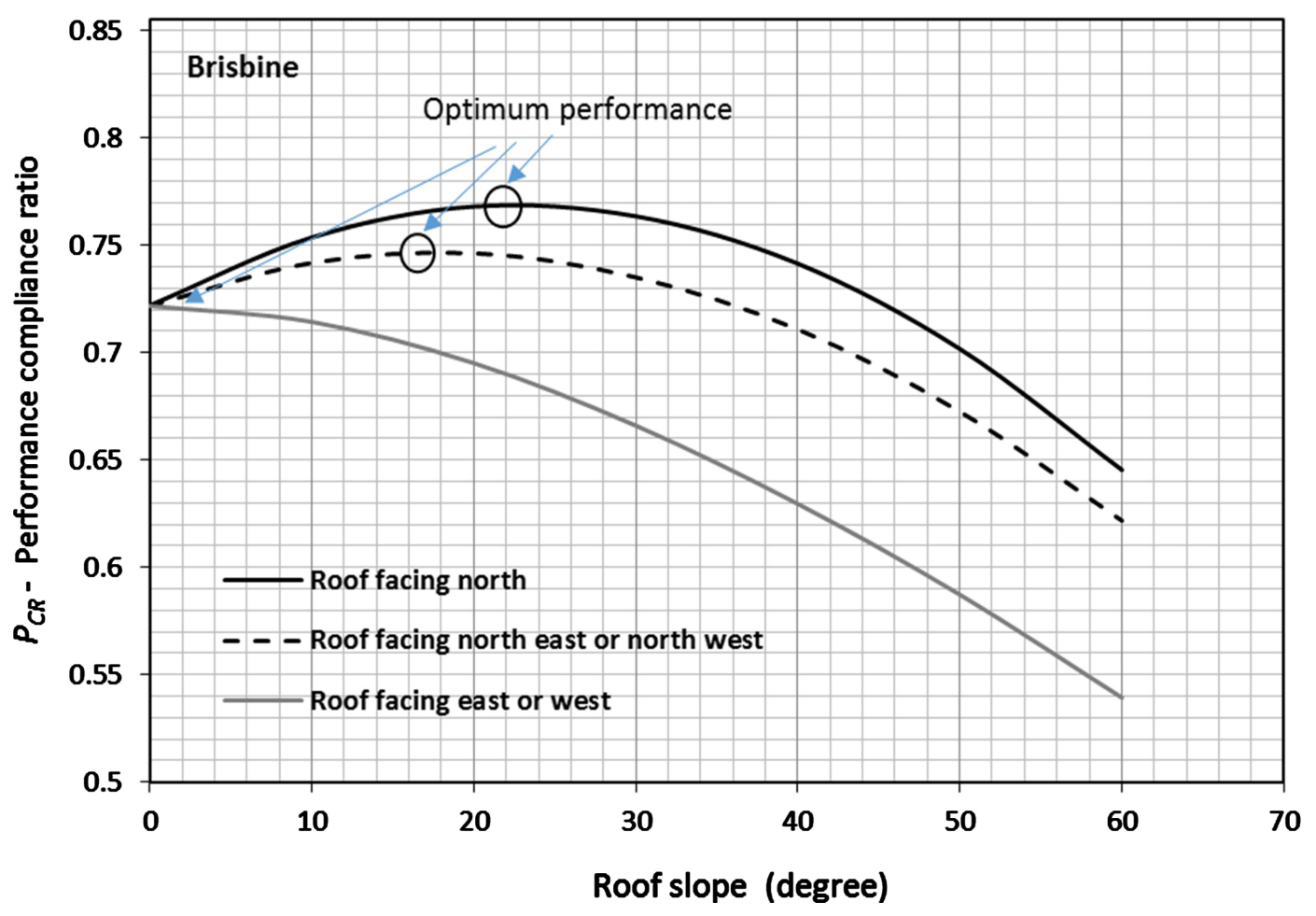

Figure 9. The optimum roof orientation and slope angle for Brisbane.

when the roof inclination is around $23^{\circ}$ and azimuth angle is 0 (toward north). The range of roof slop angle given in these two figures (from $0^{\circ}$ to $60^{\circ}$ ) is selected to cover the majority of roof angles that may exist in building designs. We can conclude from Figure 9 and Figure 10 that PV panel orientation has more influence on $P_{C R}$ than sites latitude. It can be observed that the roof top PV system at a certain site can never reach the PV array maximum capacity unless the 


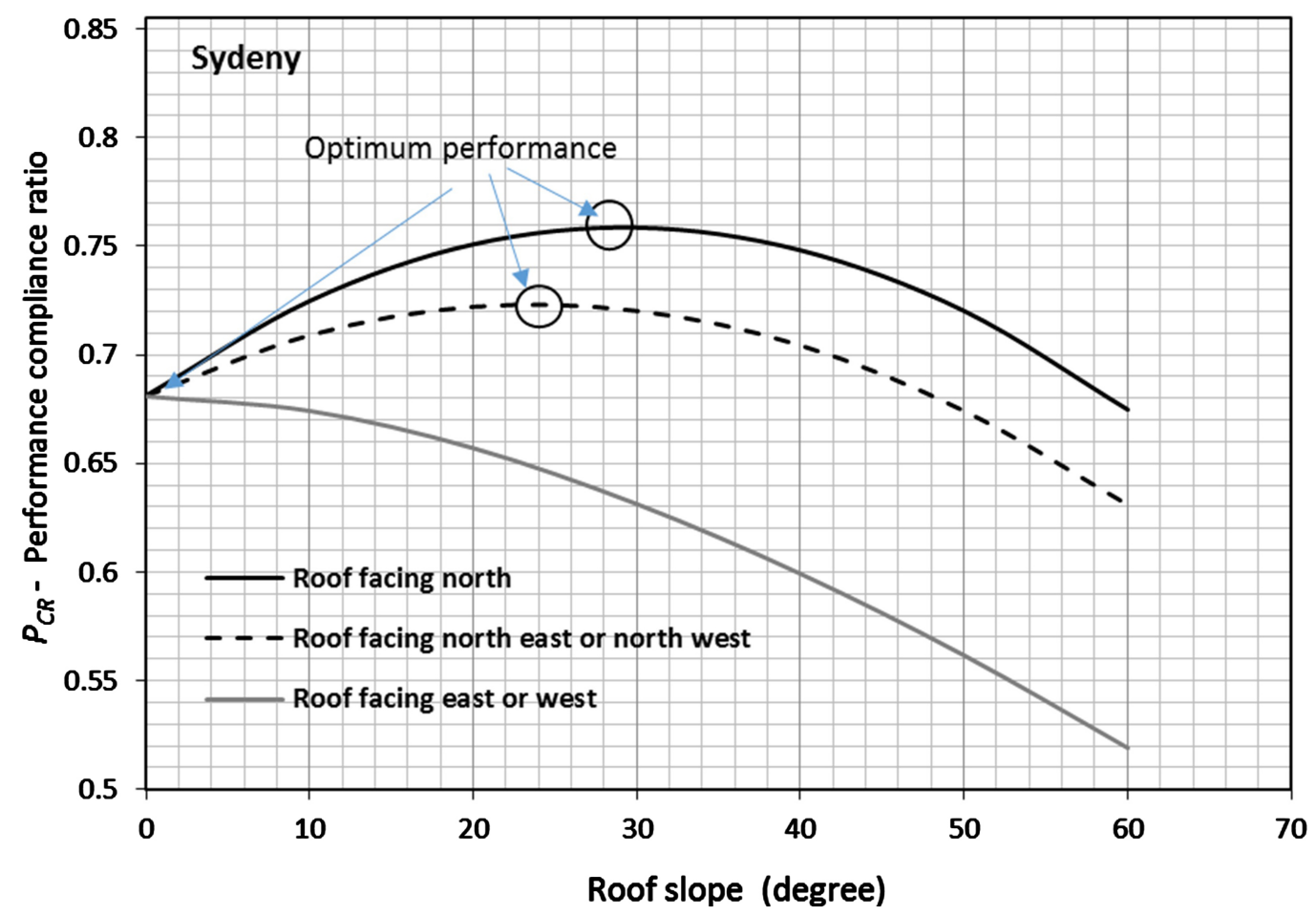

Figure 10. The optimum roof orientation and slope angle for Sydney.

system has two solar tracking axis. The worse design of the rooftop PV system orientation (roof facing east or west at roof slop $23^{\circ}$ ) may cause 32\% - 35\% drop of the tracking mode capacity. Similar charts can be constructed for different major cities or latitudes to be used by energy provider or PV installers to identify the value of $P_{C R}$ directly if roof orientation and slope angle are known.

\section{PV System Output Calculator}

The proposed performance indicator $P_{C R}$ of the PV system can be used to develop a friendly user calculator to measure the long term output of the PV rooftop systems that can be used by energy providers or PV system installers. The actual capacity (kWh) of any PV system can be estimated then by using the following equation with the help of the charts proposed in Figure 8 and Figure 9:

$$
E_{c}=H_{s h} \times P_{c} \times P_{C R}
$$

where, $E_{c}$-Energy capacity (kWh)

$H_{s h}-$ Peak sun hours per day on a sun tracking plane (h)

$P_{c}-$ Rated power capacity of $\mathrm{PV}$ panels at $1 \mathrm{~kW} / \mathrm{m}^{2}$ solar irradiance, $(\mathrm{kW})$

$P_{C R}-$ Performance compliance ratio from roof orientation chart at a certain latitude

The daily amount of solar irradiation striking any surface varies from sunrise to sunset due the sun's position in the sky. A peak sun-hour is the arbitrary day light hours that can offer a $1 \mathrm{~kW} / \mathrm{m}^{2}$ solar irradiance steadily to provide maximum DC output from the PV panels of zero solar incident angle (see conditions 1, 2 in Table 1$)$. Therefore, the average peak sun hours per day $\left(H_{s h)}\right.$ can be cal- 
culated from the following equation:

$$
H_{\text {sh }}=E_{\max }\left(\mathrm{kWh} / \mathrm{m}^{2}\right) /\left(1 \mathrm{~kW} / \mathrm{m}^{2} \text { solar irradiance }\right)
$$

where, $E_{\max }-$ Maximum energy produced by the same PV system with two axis solar tracking mode $\left(\mathrm{kWh} / \mathrm{m}^{2}\right)$.

The value of $H_{s h}$ at different sites in Australia presented in Table 2 represents the value of $E_{\max }$ calculated from the PVSYST package at the specified sites. This table can be used in conjunction with Equation (9) and the PV panel orientation chart similar to Figure 9 and Figure 10 to find the value of the energy capacity of any PV system.

Equation (9) is quite beneficial for energy providers to investigate the actual energy production from the PV grid connect systems network. An example of such a network is presented in Figure 11 which shows different type of rooftop PV system installations in one of Sydney's residential suburbs. It is quite clear that the PV panel orientation represented by the arrows adjacent to each roof is different in this suburb. While about $40 \%$ of the PV panel installations are toward the identical $\mathrm{N}$ orientation, $40 \%$ are toward $\mathrm{W}$ or $\mathrm{E}$ and $20 \%$ toward $\mathrm{NE}$ or NW. The $P_{C R}$ for these orientation at Sydney are found from Figure 10 at roof

Table 2. Average daily peak sun hours on a sun tracking plane.

\begin{tabular}{ccc}
\hline City & Latitudes $\left(^{\circ}\right)$ & Peak sun hours \\
\hline Darwin & $12.2^{\circ}$ & 5.7 \\
Alice Springs & 23.5 & 7.0 \\
Brisbane & 27.5 & 4.9 \\
Perth & $31.6^{\circ}$ & 6.1 \\
Sydney & $33.5^{\circ}$ & 4.9 \\
Adelaide & $34.5^{\circ}$ & 5.7 \\
Canberra & $35.3^{\circ}$ & 5.2 \\
Melbourne & $37.5^{\circ}$ & 4.7 \\
Hobart & $42.5^{\circ}$ & 4.8 \\
\hline
\end{tabular}

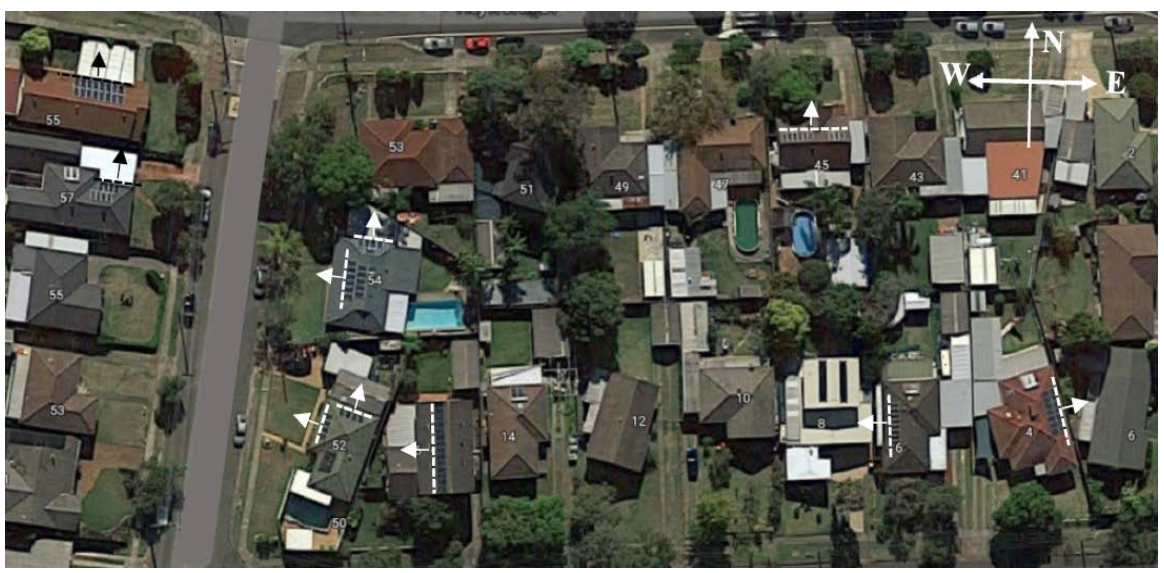

Figure 11. Rooftop installation in one of Sydney's residential suburb. 
angle $23^{\circ}$ and they are equal to $0.75,0.66$, and 0.72 respectively. Assuming that each of the 10 installations in Figure 10 has a capacity of $1 \mathrm{~kW}$ and by selecting peak sun hour $(4.9 \mathrm{~h})$ for Sydney from Table 2 then the total energy capacity $E_{c}$ of this suburb given by Equation (9) is,

$E_{c}=4.9 \mathrm{~h} \times(0.4 \times 0.75+0.4 \times 0.66+0.2 \times 0.72) \times 10 \mathrm{~kW} \times 365=12663 \mathrm{kWh} /$ year.

Referring to Sydney PV installation map [23] the average PV system capacity in Sydney is reported to be between $3.73-4.14 \mathrm{kWh} / \mathrm{kWc} /$ day which gives annual energy value for the same suburb of Figure 11 between 13,614 - 15,001 $\mathrm{kWh} /$ year. The estimated value of $E_{c}$ is less than the range given by the PV installation map by $7 \%$ due to the consideration of the different PV rooftop system orientation.

\section{Conclusion}

In this paper, six types of performance indicators found in the literature $\left(P_{R}\right.$, $\eta_{\text {system }} S F, C_{F}, Y_{F}$, and $\left.P I\right)$ were analysed. The performance ratio $\left(P_{R}\right)$ and the capacity factor $\left(C_{F}\right)$ methods for assessing the $\mathrm{PV}$ systems are readjusted from the benefit of the end user to show the effect of PV panels' orientation on the estimation of the PV system energy capacity. The developed indicator which is called performance compliance ratio $\left(P_{C R}\right)$ considers the effect of different designs of roof orientation and inclination that may exist in a suburban rooftop PV system network. The analysis conducted on the new performance indicator showed that $P_{C R}$ cannot be correlated with the latitude as in the conventional method and its value depends on the PV panel's frame design restrictions (e.g., orientation, or inclination) and weather conditions. The proposed performance indicator was used to develop a friendly user calculator of PV system output that can be used by energy providers and PV system installers to evaluate the output of the PV grid connect network without using sophisticated softwares. Charts for $P_{C R}$ and roof orientation angles were developed to identify optimum rooftop PV panel design. A case study of a suburban residential PV systems network was presented to show the benefit of the proposed method in estimating the capacity of the PV systems' network. The results showed that the method of this study gives more accurate values of the energy capacity of the PV rooftop systems than the available PV installation maps due to the consideration of the different roof designs. For future work the $P_{C R}$ charts will develop for different latitudes to make the friendly user calculator of PV system output of this work globally applicable.

\section{References}

[1] Duffie, J. and Beckman, W. (2013) Solar Engineering of Thermal Processes. John Wiley \& Sons, Hoboken, 755 p.

[2] Kalogirou, S. (2014) Solar Energy Engineering-Processes and Systems. 2nd Edition, Elsevier, $492 \mathrm{p}$.

[3] Pearsall, N. (2016) The Performance of Photovoltaic (PV) Systems: Modelling, Measurement and Assessment. Elsevier, Woodhead Publishing, 8 p. 
[4] Akash, S., Sudhakar, K. and Baredar, P. (2016) Design Simulation and Economic Analysis of Standalone Roof Top Solar PV. Solar Energy, 136, 437-449.

[5] Kymakis, E., Kalykakis, S. and Papazoglou, T. (2009) Performance Analysis of a Grid Connected Photovoltaic Park on the Island of Crete. Energy Conversion and Management, 50, 433-438. https://doi.org/10.1016/j.enconman.2008.12.009

[6] Kumar, K., Sundareswaran, K. and Venkateswaranc, P. (2014) Performance Study on a Grid Connected $20 \mathrm{kWp}$ Solar Photovoltaic Installation in an Industry in Tiruchirappalli (India). Energy for Sustainable Development, 23, 294-304.

[7] Leloux, J., Narvarte, L. and Trebosc, D. (2012) Review of the Performance of Residential PV Systems in France. Renewable and Sustainable Energy Reviews, 16, 1369-1376. https://doi.org/10.1016/j.rser.2011.10.018

[8] Leloux, J., Narvarte, L. and Trebosc, D. (2012) Review of the Performance of Residential PV Systems in Belgium. Renewable and Sustainable Energy Reviews, 16, 178-184. https://doi.org/10.1016/j.rser.2011.07.145

[9] Odeh, S. (2016) Long Term Assessment of a Grid Connected solar PV System in Sydney. Journal of Energy and Power Engineering, 10, 591-599.

[10] Odeh, S. (2017) The Development of a Performance Indicator for PV Power Generators. Photovoltaic Technology, World Renewable Energy Congress XVI, Perth, 5-9 February 2017.

[11] Ayompea, L., Duffya, A., McCormackb, S. and Conlonc, M. (2011) Measured Performance of a $1.72 \mathrm{~kW}$ Rooftop Grid Connected Photovoltaic System in Ireland. Energy Conversion and Management, 52, 816-825. https://doi.org/10.1016/j.enconman.2010.08.007

[12] The European Standard, Photovoltaic SYSTEM Performance Monitoring-Guidelines for Measurement (1998) Data Exchange and Analysis; EN 61724, BSI, UK.

[13] Ueda, Y., Kurokawa, K., Itou, T., Kitamura, K., Akanuma, K., Yokota, M. and Sugihara, H. (2008) Advanced Analysis of Grid-Connected PV System's Performance and Effect of Batteries. Electrical Engineering in Japan, 164, 247-258. https://doi.org/10.1002/eej.20660

[14] Odeh, S. and Abu-Mulaweh, H. (2012) Design and Development of Experimental Setup of Hybrid PV/Thermal Collector. Global Journal of Engineering Education, 14, 170-176.

[15] Fujisawa, T. and Tani, T. (2001) Optimum Design for Residential Photovoltaic-Thermal Binary Utilization System by Minimizing Auxiliary Energy. Electrical Engineering in Japan, 137, 28-35. https://doi.org/10.1002/eej.1077

[16] Photovoltaics Report (2017) Fraunhofer Institute for Solar Energy Systems, ISE with support of PSE AG; Freiburg, Germany.

[17] Copper, J., Bruce, A., Spooner, T., Calais, M., Pryor, T. and Watt, M. (2013) Australian Technical Guidelines for Monitoring and Analysing Photovoltaic Systems, Version 1, Australian PV institute; APVI.

[18] Pless, S., Deru, M., Torcellini, P. and Hayter, S. (2005) Procedure for Measuring and Reporting the Performance of Photovoltaic Systems in Buildings, Technical Report; NREL/TP-550-38603.

[19] Bureau of Meteorology Australian Government (2017) Climate Data Online. http://www.bom.gov.au/climate/data/

[20] Odeh, S. and Behnia M. (2009) Development of PV Module Efficiency Using Water Cooling. Heat Transfer Engineering, 30, 499-505.

https://doi.org/10.1080/01457630802529214 
[21] Mermoud, A. (2012) PVSYST Photovoltaic Software. The University of Geneva; Switzerland.

[22] National Construction Code (2017) Building Code of Australia Class 2 to Class 9 Building, Volume 1, ABCB.

[23] Australian PV Institute (APVI) (2017) Mapping Australian Photovoltaic Installations. http://pv-map.apvi.org.au/historical\#10/-33.7700/150.8917 